\title{
Renal Diseases and Islamic Religious Beliefs and Practices
}

Rabbani Khorasgani M* and Atyabi SR

Department of Biology, Faculty of Sciences, University of

Isfahan, Isfahan, Iran

*Corresponding author: Rabbani Khorasgani M, Department of Biology, Faculty of Sciences, University of Isfahan, Hezar jreeb Street, Isfahan 81746-73441, Iran

Received: February 16, 2018; Accepted: March 15, 2018; Published: March 23, 2018

\section{Keywords}

Religious; Medicine; Renal; Disease; Safety

\section{Letter}

Today, the studies about connections between medicine and religious beliefs have been developed and discussed in prevention, treatment, and control of diseases. The quantity and quality of the relationship between Islamic approach to health and different aspects of human health have been interested increasingly. Some important principles of Islamic approach to health could be regarded as the following:

1. Body and soul relatedness

2. Priority of disease prevention to treatment

3. Importance of maintaining personal body hygiene

4. Necessity of cleanliness before some worshipping duties, especially through ablution
5. Male infant circumcision

6. Sexual hygiene and abstinence from risky sexual behaviors

7. Islamic life style including suitable nutrition, sleeping and awareness, working and etc. may be play important roles in control and prevention from renal diseases. Furthermore, the dimension of spirituality can provide support in difficult situations in patients with advanced Chronic Kidney Disease (CKD), End-Stage Renal Disease (ESRD), Chronic Renal Failure (CRF) and other renal diseases. Based on this context, beneficial use of Islamic instructions may be considered for two aspects of urinary system related disorders;

1. Instructions for physical health with better body systems functioning that can be regarded as practical strategies for prevention of renal diseases and therefore less time spent in hospital and lower mortality. Some specific rules for urination such as avoiding of delayed urination in Islamic texts may help to prevention of kidney dysfunctions.

2. Mental wellbeing, with provide support in difficult situations such as patient stress that may be helpful for human living.

It is recommended to study Islamic approach to health carefully for beneficial uses of them for prevention and control of urinary system diseases. 